\title{
Erratum to: Effects of diurnal variations in temperature on non-accidental mortality among the elderly population of Montreal, Québec, 1984-2007
}

\author{
Maria Vutcovici • Mark S. Goldberg • Marie-France Valois
}

Published online: 13 June 2013

(C) ISB 2013

Erratum to: Int J Biometeorol

DOI 10.1007/s00484-013-0664-9

The 3rd column of table 3 should read '99th percentile relative to the 75 th percentile ${ }^{\mathrm{b}}$.

The online version of the original article can be found at http://dx.doi.org/ 10.1007/s00484-013-0664-9.

M. Vutcovici $(\bowtie)$

Division of Gastroenterology, McGill University Health Center,

Royal Victoria Hospital, 687 Pine Avenue West, RVH,

Pavilion Ross R4.32, Montreal, Québec H3A 1A1, Canada

e-mail: maria.vutcovici@mail.mcgill.ca

M. S. Goldberg • M.-F. Valois

Department of Medicine, McGill University,

Royal Victoria Hospital, Montreal, Canada

M. S. Goldberg $\cdot$ M.-F. Valois

Division of Clinical Epidemiology, McGill University Health

Center, Montreal, Canada 